\title{
BMJ Open Medicinal plants used among pregnant women in a tertiary teaching hospital in Jimma, Ethiopia: a cross-sectional study
}

\author{
Seid Mussa Ahmed (D) ,1,2 Johanne Sundby, ${ }^{1}$ Yesuf Ahmed Aragaw, ${ }^{3}$ \\ Hedvig Nordeng ${ }^{4}$
}

To cite: Ahmed SM, Sundby J, Aragaw YA, et al. Medicinal plants used among pregnant women in a tertiary teaching hospital in Jimma, Ethiopia: a cross-sectional study. BMJ Open 2021;11:e046495. doi:10.1136/ bmjopen-2020-046495

- Prepublication history and additional online supplemental material for this paper are available online. To view these files, please visit the journal online (http://dx.doi.org/10. 1136/bmjopen-2020-046495)

Received 03 November 2020 Accepted 07 July 2021

Check for updates

(C) Author(s) (or their employer(s)) 2021. Re-use permitted under CC BY-NC. No commercial re-use. See rights and permissions. Published by BMJ.

For numbered affiliations see end of article.

Correspondence to

Seid Mussa Ahmed; seidma@studmed.uio.no

\section{ABSTRACT}

Objective The aim of this study was to investigate and describe the use of medicinal plants during pregnancy among women admitted in the Maternity and Gynaecology wards at Jimma University Medical Centre (JUMC) in the southwest Ethiopia.

Design Cross-sectional study.

Setting Maternity and Gynaecology wards at JUMC. Participants 1117 hospitalised pregnant women or postpartum women.

Main outcome measures Our primary outcomes of interest were the prevalence of use, types of medicinal plants used and their utilisation among pregnant women. Methods Data were collected through structured face-toface interviews of pregnant women or postpartum women and review of patient medical records between February and June 2017.

Results Overall, $28.6 \%$ of the women reported use of at least one medicinal plant during the pregnancy. Twenty-seven different types of medicinal plants were used. The most commonly used medicinal plants were Linum usitatissimum L. (flaxseed—use with caution) $22.0 \%$, Ocimum lamiifolium L. (damakessie - safety unknown) 3.6\% and Carica papaya L. (papaya-use with caution) $3.1 \%$. The most common reason for use was preparation, induction or shortening of labour. Lack of access to health facility (mainly health posts), admission to maternity ward, khat chewing and alcohol consumption were the strongest predictors of medicinal plants use during pregnancy $(O R>2)$. Only five medicinal plants used by women had sufficient evidence to be classified as safe to use in pregnancy.

Conclusions Almost one-third of women at the tertiary hospital in Ethiopia reported use of medicinal plants during pregnancy, most frequently to prepare, induce, reduce the intensity or shorten duration of labour. Increased awareness about potential benefits or risks of medicinal plants use during pregnancy among healthcare professionals and patients, and increased access to childbirth providing healthcare facilities are important in order to promote safer pregnancies and better health outcomes for women and their unborn children.

\section{BACKGROUND}

Medicinal plants have been used for preventive and therapeutic purposes since time immemorial. ${ }^{1}$ Medicinal plants refer to a variety of plants that have medicinal characteristics. ${ }^{2}$

\section{Strengths and limitations of this study}

- It was the first study in Ethiopia that used large sample size, assessed the use of medicinal plants among pregnant women in an in-patient setting and attempted to classify the medicinal plants.

- The data collectors, pharmacists and nurses, were from the study area with previous data collection experience. Their knowledge about the healthcare system, culture, local languages and medicinal plants was vital for the face-to-face interviews with the women and clearly contributed to improving the response rate and the quality of collected data.

- Although it was conducted in a large tertiary teaching hospital in southwest Ethiopia, it may not be representative of the entire country, nor women who access healthcare in secondary or primary care.

- Data were collected based on self-report of pregnant women and thus depended on her recall and accuracy of reporting, as well as her knowledge about these medicinal plants, therefore, medicinal plant use early in pregnancy was probably under-reported.

- Among the postpartum women, there may be a risk of recall bias as women with negative pregnancy outcomes may try to recall use to a greater extent than women with a healthy infant.

WHO estimates that $65 \%-80 \%$ of the world's population in developing countries depend on medicinal plants for primary healthcare. ${ }^{3}$ Women are recognised to be the main users of medicinal plants, and this widespread use also extends into pregnancy. ${ }^{45}$

Ethiopia is a landlocked country with a population of approximately 110 million. ${ }^{6}$ It is a multiethnic, multicultural and multireligious nation where Christians predominate in the northern highlands and central Ethiopia and Muslims predominate in the north-east, east, south-east and southwest. ${ }^{7}$ More than $80 \%$ of the population lives in rural areas and $70 \%$ of the population are employed in agriculture. ${ }^{6}$ The birth rate is 31 births per 1000 inhabitants and infant mortality rate is 
35 deaths per 1000 live births. ${ }^{6}$ Maternal mortality rate is high with 4 deaths per 1000 live births (world ranking 26th). ${ }^{6}$ Total fertility rate is four children born per woman, and mother's mean age at first birth is 20 years. ${ }^{6}$ Physician density is only one per 12500 inhabitants. ${ }^{6}$ Around 80\% of the population in Ethiopia use traditional medicine, of which over $95 \%$ are of plant origin. ${ }^{8}$ The extensive use of medicinal plants in the country is often linked to an array of unique flora, ${ }^{8}$ cultural acceptability of healers and local pharmacopoeias, the belief that medicinal plants are natural and thus safer to use and are physically accessible and economically affordable. ${ }^{459}$

Maternal mortality (353 deaths per 100, 000 live births) and neonatal mortality (28 deaths per 1000 live births) in Ethiopia are among the highest in the world and are associated with a range of factors. ${ }^{10}$ In most African countries like Ethiopia, modern healthcare facilities and medicine are inaccessible or unaffordable. ${ }^{411}$ For this reason, many women rely on medicinal plants for their primary healthcare needs as an accessible and lower cost alternative ${ }^{4}$ and only seek professional health services when the situation worsens. ${ }^{11}$

Studies conducted in Ethiopia reported prevalence of medicinal plants use in pregnancy ranging from $2 \%$ to $73 \%,{ }^{4}$ with ginger being the most commonly used plant, and nausea and vomiting in pregnancy (NVP) and common cold the most common reasons for use. ${ }^{9} 1112$ Many sociodemographic characteristics including residence place, marital status, family size, education level, age and employment status were found to be strong predictors of use. ${ }^{42-15}$ Prevalence figures ranging from $4 \%$ to $100 \%$ were reported in other African countries. ${ }^{4}$ Studies in developed countries where medicinal plant traditions may play a less strong role also reported a widespread use of medicinal plants in pregnancy, with Australia $11 \%-56 \%,{ }^{16}$ the USA and Canada $4 \%-96 \%{ }^{16} 17$ and Europe $0.9 \%-69 \% .{ }^{16} 18$

Concerns have been raised about safety of medicinal plants during pregnancy. ${ }^{48-21}$ A recent multinational study reported that only $22 \%$ of the medicinal plants used by pregnant women were found safe to use in pregnancy. ${ }^{21}$ Similarly, a study from Asia showed that only $39 \%$ of the most commonly used medicinal plants by expectant women were safe to use in pregnancy. ${ }^{19}$

Although medicinal plants play a significant role in traditional medicine during pregnancy, childbirth and postpartum care,${ }^{420}$ research on their use in the management of pregnancy related illnesses is still largely limited. ${ }^{42} 22$ The aims of this study were therefore to determine the prevalence of use and types of medicinal plants used among pregnant women admitted in the Maternity and Gynaecology wards at Jimma University Medical Centre (JUMC), Southwest Ethiopia. This included identifying women's information on the most commonly used medicinal plants, the reasons for use and factors associated with such use. The secondary aims were to assess women safety concerns and, who recommended use of the medicinal plants during pregnancy.

\section{SUBJECTS AND METHODS}

\section{Study design and setting}

A hospital based cross-sectional study was conducted in the Maternity and Gynaecology wards at JUMC. JUMC is one of the oldest and largest public teaching University hospitals in the country located in Jimma city, 350 kilometres south-west of Addis Ababa (the capital city of Ethiopia) ${ }^{2324}$ The referral hospital provides tertiary level medical care for about 20 million people coming from the whole south-west Ethiopia. ${ }^{23}$ Obstetrics and Gynaecology department of the medical centre has a patient load of approximately 7600 inpatients and 11600 outpatients each year with bed capacity of around $265 .^{24}$

Obstetrics and Gynaecology department has two inpatient wards; Gynaecology ward and Maternity ward (which includes maternity, labour and delivery ward and maternity operation theatre). ${ }^{23}$ Obstetric patients with 28 weeks of pregnancy or higher as well as women in labour are admitted in the maternity ward. On the other hand, women with a gestational length of less than 28 weeks are cared for at the gynaecology ward. The gynaecology ward also manages and treats gynaecological disorders in non-pregnant women.

\section{Study population and sample size}

Hospitalised pregnant or postpartum women in the Maternity and Gynaecology wards at JUMC were invited to participate in the study during normal working hours. Participants were consecutively informed about the aim and procedures of the study and written informed consent was obtained from each study participant. Pregnant or postpartum patients aged $\geq 18$ years admitted in the Maternity/Labour and Gynaecology wards at the time of data collection and willing to participate were included in the study. On the other hand, women who were too ill to participate, hard of hearing, unable to speak or mentally disabled, under 18 years of age, admitted for less than 4 hours, and non-pregnant women admitted in the gynaecology ward were excluded from the study.

Single population proportion Kish formula ${ }^{25}$ was used to determine the sample size based on the following assumptions; $50 \%$ expected prevalence medicinal plant use (since there is no previous study conducted on the prevalence of medicinal plant use among hospitalised pregnant patients prior to admission), $5 \%$ level significance, $80 \%$ power, and an error margin of $3 \%$. After adding a 5\% non-response rate, a final sample size of 1121 pregnant women was required.

\section{Data collection and procedures}

Hospitalised pregnant and postpartum women were consecutively interviewed from February to June 2017. A pretested interview guided structured questionnaire, based on interviews and data extraction form were used for data collection. Nine trained pharmacists and nurses from the study area, with close supervision of one of the investigators, conducted all interviews and data extractions. The questionnaire contains questions about 
the women's background, pregnancy-related illnesses and use of medicinal plants.

After a thorough review of the literature, ${ }^{9} 12222627$ with special focus on prior studies in African countries, the authors developed the survey questionnaire. It was developed in English and then translated into Amharic and Afan Oromo languages (the predominant local languages) to suit the target population. The questionnaires were translated back into English by other persons to confirm the validity. Lecturers fluent in English and their own local language from Jimma University with previous experience of translating questionnaires performed the translation and back translation of the study questionnaire. The data collection tool was then piloted on a sample of 30 hospitalised pregnant or lactating women at Shenen Ghibe district hospital found in Jimma city, and based on the results from the pilot, list of 25 commonly used medicinal plants and open-ended questions were included. Plant scientific names were verified with The Plant List ( www.theplantlist.org). Final version of the questionnaire contained 77 items, with multiple choice, and openended questions (online supplemental table 1).

Treatment related characteristics, pregnancy characteristics, pregnancy outcomes and other medical information were retrieved from patients' medical record using data extraction forms. Following the pretest, the data extraction form required minor revisions to improve comprehension and order (online supplemental table 2).

\section{Measures}

\section{Use of medicinal plant}

Study participants were specifically asked about the use in pregnancy of 25 commonly used medicinal plants: Linum usitatissimum L., Ocimum lamiifolium L., Zingiber officinale Roscoe., Allium sativum L., Trigonella foenum-graecum L., Nigella sativa L., Ruta chalepensis L., Eucalyptus globulus Labill., Cinnamomum verum J.Presl, Taverniera abyssinica A. Rich, Artemisia abyssinica Sch.Bip. ex A.Rich., Croton macrostachyus Hochst., Echinops kebericho Mesfin, Hagenia abyssinica (Bruce ex Steud.) J.F.Gmel., Vernonia amygdalina Del., Brassica nigra (L.) K.Koch, Zehneria scabra Sond., Artemisia afra Jacq. ex Willd., Lepidium satioum L., Carica papaya L., Foeniculum vulgare Mill., Coriandrum sativum L., Ocimum basilicum L., Datura stramonium L. and Securidaca longipedunculata Fresen. The above listed medicinal plants were selected based on previous ethnopharmacological studies in Ethiopia and elsewhere in Africa ${ }^{9} 2829$ and were presented to the women by mentioning the local names of the plants. The women were also asked if they had used any other medicinal plant during pregnancy, labour or breastfeeding.

Details of use of medicinal plants was assessed by a series of questions including use of medicinal plant during pregnancy, type of medicinal plant used, reason for use and utilisation (part of plant used, method of preparation, mode of use, type of solvent, type of flavouring, dosage form, dosage, measures of formulation, route of administration, frequency of administration, duration of treatment, and episodes of use). Women were also asked about who recommended them the use of medicinal plants in pregnancy.

Information about women's safety concerns and experiences with use of medicinal plants in pregnancy was collected, and we included questions about beliefs about harmfulness, precautions to be taken and whether she had experienced any side effects or adverse effects after use of medicinal plants in pregnancy.

Reference text books ${ }^{30-32}$ and literature reviews ${ }^{4} 1921$ were used to evaluate safety of the medicinal plants in pregnancy, and classify them into four safety categories, namely safe to use in pregnancy, use with caution, potentially harmful and information unavailable for use in pregnancy (online supplemental table 3). Information from animal studies were used if human studies were lacking. If a medicinal plant preparation was composed of two or more plants, each plant was individually evaluated and classified.

\section{Women's background characteristics}

Sociodemographic information including age, religion, residence place, occupation, family size, ethnic group, marital status, educational level, access to modern health facility and walking distance to the facility were collected.

\section{Maternal diseases, pregnancy-related illness and treatments}

Detailed information about the woman's obstetrics and gynaecology history, history of adverse pregnancy outcome, medical history and medication experience, and social drug use were included. Pregnant women were specifically asked about 24 common pregnancy ailments and related symptoms: common cold/influenza, pain in back, neck or shoulder, headache, heartburn/reflux problems, abdominal cramps/ache, preparation for labour, induction of labour, expel retained placenta, postpartum bathing, well-being and nourishing fetus, leg/foot swelling, gestational hypertension, gestational diabetes, gastritis/burning sensation, constipation, general well-being, nausea, vomiting, emergency illnesses, urinary tract infection, depression, joint pain, sleeping problems and mental well-being. Participants were also asked whether they had used any treatment against ailments or pregnancy related conditions, whether they had had any other diseases or illnesses and, if yes, the name of any treatment received.

In addition to the face-to-face interview questionnaire, information about pregnancy characteristics, pregnancy outcomes and other obstetrics information including gestational age, parity, gravidity, mode of delivery and length of hospital stay were collected using a data extraction form. Moreover, maternal and perinatal outcomes of the current pregnancy were collected. Data were extracted through review of patients' medical cards.

\section{Statistical analysis}

The final data were checked for completeness, and responses were entered into and analysed using the Statistical Package for the Social Sciences (SPSS) software V.25.0 for Windows (IBM SPSS Statistics). Respondents 
were categorised as users if they used at least one type of medicinal plant in their index pregnancy, whereas others were categorised as non-users. Routine meals and vitamin supplements were excluded.

Descriptive statistics were used to calculate the prevalence $(\%)$ of medicinal plants use in pregnancy, reasons for use and information sources. Univariate and multivariate logistic regression analysis was used to identify significant factors associated with medicinal plant use. Logistic regression was expressed as crude and adjusted ORs with 95\% CIs. First, the univariate logistic regression model was fit for all explanatory variables. From this, the multivariate model was built using purposeful selection of candidate variables based on a bivariate $p \leq 0.05$. We then fit a reduced model by removing variables having no role $(\mathrm{p}>0.05)$. A $\mathrm{p}<0.05$ was considered statistically significant. Robustness of the multivariable model was checked using the Hosmer-Lemeshow test.

\section{Patient and public involvement}

Although there is a community representative in the Jimma University Institute of health Institutional Review Board, no patients or public were involved in the conception, design, conduct and planning of this study.

\section{RESULTS}

From 1137 pregnant or postpartum women invited to participate, responses from four were incomplete, and 16 declined to participate in the study resulting in 1117 participants in the final dataset (response rate 98.6\%). The median age was 25 years (IQR 22-30 years) and slightly more than half (53.3\%), lived in an urban area. The majority were married $(95.5 \%)$, had access to health facility (mainly health post) (99.1\%), and lived in an area within walking distance to the nearest health facility not more than $30 \mathrm{~min}(66.4 \%)$. A substantial number were Muslims (65.4\%), from Oromo ethnic group (69.7\%), and had a household size less than five (65.4\%). Many study participants were illiterate $(34.0 \%)$ or either attended primary school or only able to read and write $(42.3 \%)$; and were housewife $(46.9 \%)$ or farmer $(23.4 \%)$ by occupation (table 1).

In total, 28.6\% women had used one or more medicinal plant during their current pregnancy, with an average of 1.5 medicinal plants per woman (range 1-8). The majority of women $206(64.6 \%)$ used one, 78 (24.5\%) took two, $25(7.8 \%)$ took three and $7(2.2 \%)$ took four types of medicinal plants.

L. usitatissimum (flaxseed) $(77.1 \%)$, O. lamiifolium ('damakesie') (12.5\%) and C. papaya (papaya) (11.0\%) were the three most commonly used medicinal plants (table 2; online supplemental table 4). The most common reasons for the use of medicinal plants were to induce labour or to reduce the intensity and shorten duration of

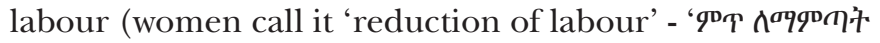

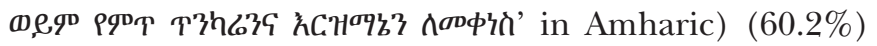
common cold/influenza $(20.4 \%)$ and preparation of

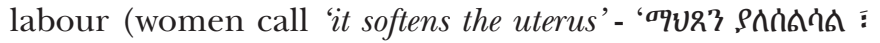

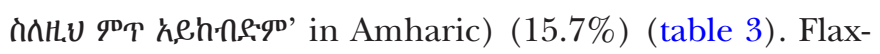
seed was the major plant employed to induce labour or to reduce the intensity and shorten duration of labour $(93.2 \%)$ and to prepare for labour (44\%). Ginger (35.4\%) was the commonly used plant for common cold/ influenza management. Most of the medicinal plants were used during labour $(32.2 \%)$, followed by third trimester $(27.2 \%)$ or in the entire pregnancy $(19.8 \%)$.

Among the 125 women admitted to the gynaecology wards, $106(84.8 \%)$ were admitted due to elective terminations and/or miscarriages and $19(15.2 \%)$ were admitted due to various pregnancy-related illnesses. Among the women with elective terminations and/or miscarriages, 19 (17.9\%) women used one or more medicinal plants during pregnancy (range 1-3): 16 used safe, 9 used medicinal plants requiring cautious, 5 potentially harmful and 11 safety unknown medicinal plants. Fivewomen who used potentially unsafe medicinal plants used Trigonella foenum-graecum (potential risk of uterine contraction and hypoglycaemic), Ruta chalepensis (potential risk of uterine contraction and emmenagogue), Cinnamomum verum (potential risk of fetal malformation and uterine contraction), Artemisia abyssinica (potential risk of toxicity, uterine contraction and emmenagogue), Croton macrostachyus (potential risk of toxicity and uterine contraction), Echinops kebericho (potential risk of cytotoxicity) and Hagenia abyssinica (potential risk of toxicity and uterine contraction) (online supplemental table 4).

Approximately three quarters of the medicinal plants were purchased at market places $(76.5 \%)$. A significant proportion of respondents $(68.3 \%)$ also collected it through family members. The large majority of women were recommended to use medicinal plants by their family members $(75.2 \%)$.

Seeds were the major medicinal plant parts used $(57.6 \%)$, dry plant material was the most common plant condition $(60.1 \%)$, sugar was the most common excipient $(27.8 \%)$ and oral was the predominant route of administration $(89.7 \%)$.

The most common dosages were measurements by water glass units $(51.7 \%)$. The most common dosage was one water glass dose $(47.5 \%)$, once per day frequency $(54.8 \%)$ and 'as many months as needed during pregnancy' duration of treatment $(32.9 \%)$. Approximately half of the respondents reported one episode of medicinal plant use (46.0\%), whereas nearly one-third reported use at several occasions during pregnancy (32.0\%) (online supplemental table 5).

\section{Factors associated with medicinal plant use}

Women in the maternity wards, not having access to a nearby health facility, having secondary school education, having chronic illness, using conventional medicines and social drugs (khat chewers and alcohol consumers) were more likely to use medicinal plants in pregnancy (table 1). Use of medicinal plants during pregnancy was not significantly associated with previous adverse pregnancy outcome, length of hospital stay, family size and gestational age. 
Table 1 Characteristics of women according to medicinal plant use during pregnancy at JUMC, Ethiopia

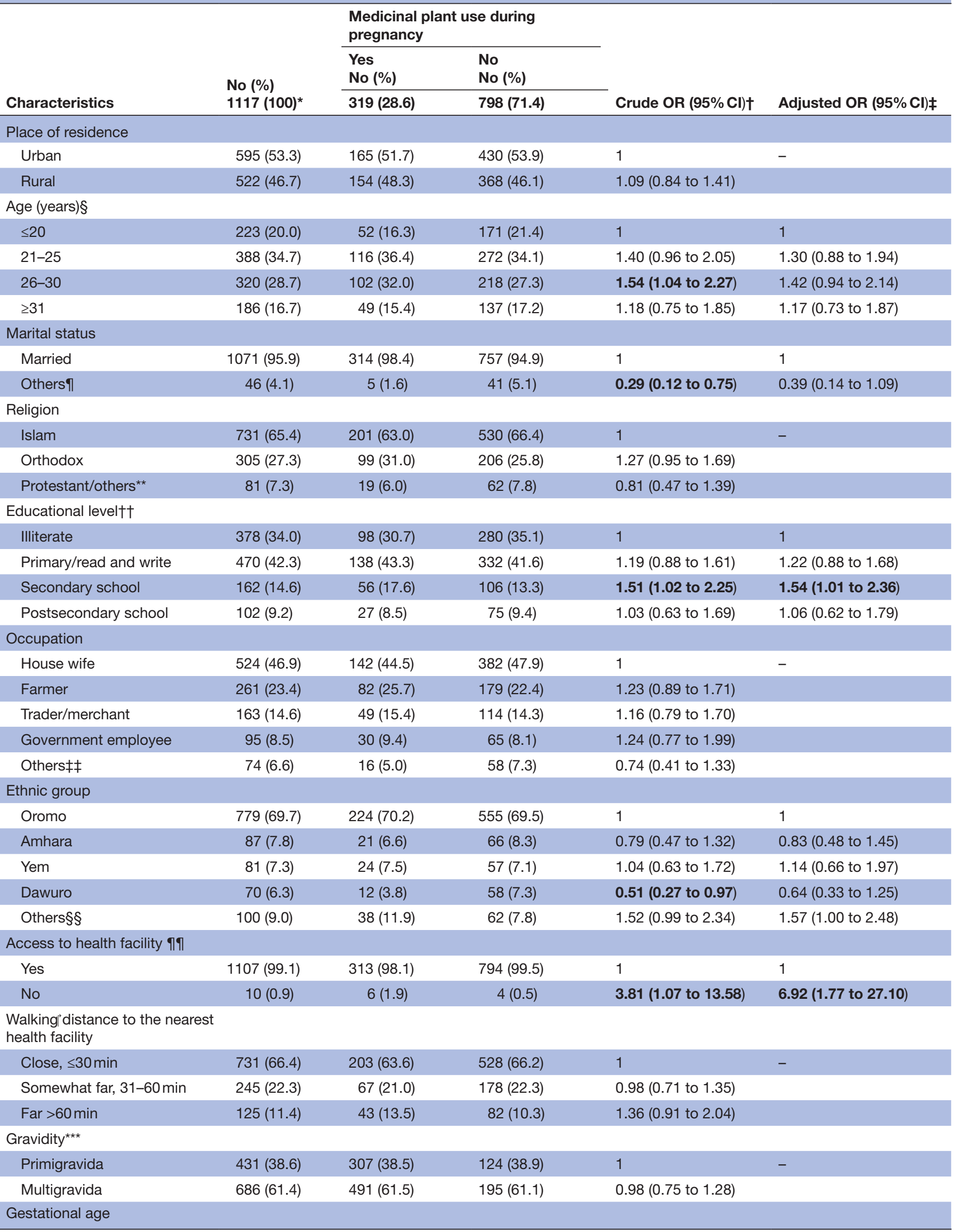


Table 1 Continued

\begin{tabular}{|c|c|c|c|c|c|}
\hline \multirow[b]{3}{*}{ Characteristics } & \multirow{3}{*}{$\begin{array}{l}\text { No (\%) } \\
1117(100)^{*}\end{array}$} & \multicolumn{2}{|c|}{$\begin{array}{l}\text { Medicinal plant use during } \\
\text { pregnancy }\end{array}$} & \multirow[b]{3}{*}{ Crude OR $(95 \% \mathrm{Cl}) \dagger$} & \multirow[b]{3}{*}{ Adjusted OR (95\% Cl)‡ } \\
\hline & & $\begin{array}{l}\text { Yes } \\
\text { No (\%) }\end{array}$ & $\begin{array}{l}\text { No } \\
\text { No (\%) }\end{array}$ & & \\
\hline & & $319(28.6)$ & $798(71.4)$ & & \\
\hline Preterm pregnancy & $231(20.7)$ & $60(18.8)$ & $171(21.4)$ & 1 & 1 \\
\hline Term pregnancy & $735(65.8)$ & $208(65.2)$ & $527(66.0)$ & 1.13 (0.81 to 1.57$)$ & 0.80 (0.52 to 1.25$)$ \\
\hline Post term pregnancy & $62(5.6)$ & $27(8.5)$ & $35(4.4)$ & 2.20 (1.23 to 3.93$)$ & 1.65 (0.85 to 3.20$)$ \\
\hline Otherst†† & $89(8.0)$ & $24(7.5)$ & $65(8.1)$ & 1.05 (0.61 to 1.83$)$ & $0.72(0.38$ to 1.36$)$ \\
\hline \multicolumn{6}{|l|}{ Patient type } \\
\hline Gynaecology ward & $125(11.2)$ & $22(6.9)$ & $103(12.9)$ & 1 & 1 \\
\hline Maternity ward & $992(88.8)$ & $297(93.1)$ & $695(87.1)$ & $2.00(1.24$ to 3.23$)$ & 2.80 (1.43 to 5.48$)$ \\
\hline \multicolumn{6}{|l|}{ 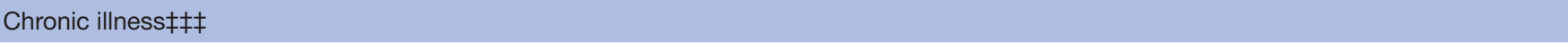 } \\
\hline No & $1061(95.0)$ & $294(92.2)$ & $767(96.1)$ & 1 & 1 \\
\hline Yes & $56(5.0)$ & $25(7.8)$ & $31(3.9)$ & 2.10 (1.22 to 3.62$)$ & $1.83(1.04$ to 3.24$)$ \\
\hline \multicolumn{6}{|c|}{ Conventional medicine use§§§ } \\
\hline No & $817(73.1)$ & $209(65.5)$ & $608(76.2)$ & 1 & 1 \\
\hline Yes & $300(26.9)$ & $110(34.5)$ & $190(23.8)$ & $1.68(1.27$ to 2.23$)$ & $1.83(1.36$ to 2.46$)$ \\
\hline \multicolumn{6}{|c|}{ Chew Khat (Catha edulis)ףা } \\
\hline No & $1052(94.2)$ & $289(90.6)$ & $763(95.6)$ & 1 & 1 \\
\hline Yes & $65(5.8)$ & $30(9.4)$ & $35(4.4)$ & 2.26 (1.36 to 3.75$)$ & 2.53 (1.46 to 4.39$)$ \\
\hline \multicolumn{6}{|l|}{ Alcohol consumption } \\
\hline No & 1071 (95.9) & $297(93.1)$ & $774(97.0)$ & 1 & 1 \\
\hline Yes & $46(4.1)$ & $22(6.9)$ & $24(3.0)$ & 2.39 (1.32 to 4.33$)$ & 2.43 (1.28 to 4.62$)$ \\
\hline \multicolumn{6}{|l|}{$\begin{array}{l}\text { Past adverse pregnancy } \\
\text { outcome }\end{array}$} \\
\hline No/not applicable & $994(89.0)$ & $275(86.2)$ & $719(90.1)$ & 1 & - \\
\hline Yes & $123(11.0)$ & $44(13.8)$ & $79(9.9)$ & 1.51 (1.00 to 2.28$)$ & \\
\hline
\end{tabular}

*Numbers may not add up to 1117 due to missing values.

†Significant findings are in bold $(p<0.05)$.

$\ddagger$ Adjusted for age, marital status, educational level, ethnic group, access to health facility, gestational age, patient type, chronic illness, conventional medicine use, chew khat, alcohol consumption.

§Median age 25 years, IQR 22-30 years.

ๆOthers includes single 41 (3.7\%), divorced $4(0.4 \%)$, widowed $1(0.1 \%)$.

**Protestant/others includes Protestant 74 (6.6), Catholic $2(0.2 \%)$, Waqqefeta $1(0.1 \%)$, missing $4(0.4)$.

$\dagger †$ Read and write: no formal education but can read and write due to literacy campaigns, traditional religious institution and informal peer learning primary school: grade 1-8, secondary school: grade 9-12; Post-secondary school: Technical and vocational school, college or university.

¥¥Others includes daily labourers 24 (2.1), students 22 (2.0), private institution workers 18 (1.6), other sectors 10(0.9\%).

$\S \S$ Others includes Gurage 41 (3.7), Silte $30(2.7)$, Kaffa $16(1.4)$, Tigre $3(0.3)$, Wolayita $3(0.3)$, mixed ethnic backgrounds $7(0.6)$.

१ीAccess to health facility means access to either primary, secondary or tertiary levels of healthcare; it mainly represents access to health posts.

***Gravidity includes the current pregnancy.

†††Women are in the first, second or third trimester of pregnancy but exact week of pregnancy is not known.

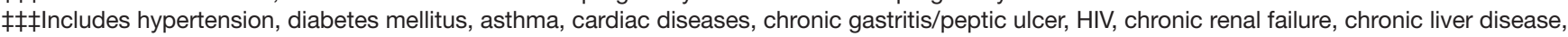
etc.

$\S \S \S R$ Rers to self-medication with conventional medicine before hospitalisation.

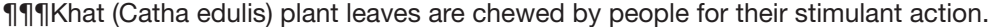

JUMC, Jimma University Medical Centre.

\section{Safety classification of the medicinal plants}

From the 27 medicinal plants used by women, five were classified as safe to use, three as requiring caution to use, eight as potentially harmful to use in pregnancy and information on eleven medicinal plants was not available in the current literature. The names and safety classification of the 27 individual medicinal plants are presented in (online supplemental table 4).
Of those pregnant women who used medicinal plants, $14.4 \%$ used safe, $12.2 \%$ harmful, $3.4 \%$ both safe and harmful and $69.9 \%$ used one or more medicinal plants that requires cautious use or safety information unavailable. Many women who used safe or harmful medicinal plants have also used one or more plants that requires cautious use or safety information unavailable. 
Table 2 Overview of the most frequently used medicinal plants during pregnancy according to number of users and the most common indications at JUMC, Ethiopia

\section{Medicinal plant (English name) (local name) Preparation method}

Linum usitatissimum L. (Flaxseed or Linseed) (Telba) Flax seeds are roasted, pounded, thoroughly mixed with water and consumed in soup form.

\section{No of users $(\mathrm{n}=319), \mathrm{n}(28.6 \%)$ \\ Most common indications (No of citations)}

$246(77.1)^{\star}$
Induction or 'reduction' of labour

(179)†

Prepare for labour (22)

Heartburn/reflux problems (19)

Constipation/obstipation (16)

Gastritis/burning sensation (14)

Abdominal cramps or ache (2)
Ocimum lamiifolium L. (No common English name)

(Damakessie)

$40(12.5)$

Adding minced fresh leaves or steeping in leaves in tea, coffee, milk or decoction or maceration of minced root are drunk, or fresh leaves are put in nostrils and sniffed

Carica papaya L. (Papaya) (Papaya)

Ripened fresh fruit is eaten or its juice is extracted and then drunk

\section{$35(11.0)$}

Mitch (19)‡

Common cold/influenza (10)

Headaches/Migraine (8)

Prevent bad smell (5)

Emergency cases/illnesses (3) Nausea (2)

\section{Prepare for labour (17)}

Heartburn/reflux problems (5) Induce labour (4)

Abdominal cramps or ache (4) Gastritis/burning sensation (3) Helminths (2)

Zingiber officinale Roscoe. (Ginger) (Zingibil) Drinking aqueous decoction or maceration, or drinking minced root with water or tea

$29(9.1)$

Common cold/influenza (23)

Nausea (4)

Vomiting (2)
Abdominal cramps (2)

$28(8.8)$

Common cold/influenza (13)

General well-being (5)

Abdominal cramps (5)

Headaches/Migraine (3)

Birdd (2)§

Prepare for labour (11)

Induce labour (6)

Gastritis/burning sensation (4)

powdered seeds in soup form

Nigella sativa L (Black seed) (Tikur Azmud)

Drinking few drops of the seed oil with tea, coffee, milk or

$21(6.4)$

Headaches/Migraine (10)

Abdominal cramps or ache (7)

Common cold/influenza (6)

Ruta chalepensis L. (Fringed rue) (Tenadam)

Adding minced fresh leaves or steeping in leaves in tea, coffee, or milk and then drunk or fresh leaves squeezed, and then drunk
$15(4.7)$

$13(4.1)$

Nausea (4)

General well-being (3)

Headaches/Migraine (2)

Mental well-being (2)

Abdominal cramps (2)

Common cold/influenza (12)

Postpartum bathing (3)

Mitch (2)

Leaves are boiled in water, patient fumigated and the vapour is inhaled

*This prevalence of use of individual medicinal plant is based on those pregnant women who used one or more medicinal plants $(\mathrm{N}=319)$. Based on the overall study participants $(\mathrm{N}=1,117)$ the prevalence of use of individual medicinal plant is, for example, Linum usitatissimum L. 22.0\%, Ocimum lamiifolium L. 3.6\%, and Carica papaya L. 3.1\%.

†'Reduction of labour': includes reduced intensity and shortened duration of labour.

‡'Mitch': a febrile illness believed to develop when strong sunlight strikes a part of the body that is sweating or unclean.

§'Birdd': an illness typified by a feeling of chills, arthralgia, myalgia, generalised body weakness, pain (particularly chest pain) and coughing. In general, it is characterised by pneumonia/influenza-like symptoms.

JUMC, Jimma University Medical Centre.

\section{Women's safety concerns and experiences}

Table 4 presents women's self-reported safety concerns and experiences with medicinal plants in pregnancy.
Safety concerns with use in pregnancy was most commonly reported for bisana (C. macrostachyus) and astenagir (D. stramonium), each by five women. Four women reported 
Table 3 Pregnancy disorders treated with medicinal plants at JUMC, Ethiopia, $n=319$

\begin{tabular}{|c|c|c|}
\hline Variables & No $(\%)^{*}$ & Most common medicinal plants (no of users) \\
\hline Induction and 'reduction' of labour† & $192(60.2)$ & $\begin{array}{l}\text { Linum usitatissimum (Flaxseed) (179) } \\
\text { Trigonella foenum-graecum (Fenugreek) (6) } \\
\text { Carica papaya (Papaya) (4) }\end{array}$ \\
\hline Common cold/influenza & $65(20.4)$ & $\begin{array}{l}\text { Zingiber officinale (Ginger) (23) } \\
\text { Allium sativum (Garlic) (13) } \\
\text { Eucalyptus globulus (Nech-bahir zaf) (12) }\end{array}$ \\
\hline Preparation for labour & $50(15.7)$ & $\begin{array}{l}\text { Linum usitatissimum (Flaxseed) (22) } \\
\text { Carica papaya (Papaya) (17) } \\
\text { Trigonella foenum-graecum (Fenugreek) (11) }\end{array}$ \\
\hline Abdominal cramps/ache & $30(9.4)$ & $\begin{array}{l}\text { Nigella sativa (Black seed) (7) } \\
\text { Allium sativum (Garlic) (5) } \\
\text { Carica papaya (Papaya) (4) }\end{array}$ \\
\hline Headache/migraine & $27(8.5)$ & $\begin{array}{l}\text { Nigella sativa (Black seed) (10) } \\
\text { Ocimum lamiifolium (Damakessie) (8) } \\
\text { Allium sativum (Garlic) (3) }\end{array}$ \\
\hline Heartburn/reflux problems & $27(8.5)$ & $\begin{array}{l}\text { Linum usitatissimum (Flaxseed) (19) } \\
\text { Carica papaya (Papaya) (5) }\end{array}$ \\
\hline Mitch $\ddagger$ & $24(7.5)$ & Ocimum lamiifolium (Damakessie) (19) \\
\hline Gastritis/burning sensation & $22(6.9)$ & Linum usitatissimum (Flaxseed) (14) \\
\hline Constipation/obstipation & $17(5.3)$ & Linum usitatissimum (Flaxseed) (16) \\
\hline General well-being & $15(4.7)$ & $\begin{array}{l}\text { Allium sativum (Garlic) (5) } \\
\text { Ruta chalepensis (Fringed rue) (3) }\end{array}$ \\
\hline Nausea & $11(3.4)$ & $\begin{array}{l}\text { Zingiber officinale (Ginger) (4) } \\
\text { Ruta chalepensis (Fringed rue) (4) }\end{array}$ \\
\hline Helminths & $6(1.9)$ & $\begin{array}{l}\text { Carica papaya (Papaya) (2) } \\
\text { Hagenia abyssinica (Kosso) (2) }\end{array}$ \\
\hline Leg/foot swelling & $5(1.6)$ & $\begin{array}{l}\text { Linum usitatissimum (Flaxseed) (1) } \\
\text { Cinnamomum verum (Cinnamon) (1) } \\
\text { Croton macrostachyus (Bisena) (1) } \\
\text { Veronia amygdalina (Grawa) (1) } \\
\text { B'auu (1) }\end{array}$ \\
\hline Prevent bad smell & $5(1.6)$ & Ocimum lamiifolium (Damakessie) (5) \\
\hline Strong craving & $5(1.6)$ & $\begin{array}{l}\text { Linum usitatissimum (Flaxseed) (1) } \\
\text { Carica papaya (Papaya) (1) } \\
\text { Nigella sativa (Black seed) (1) } \\
\text { Ruta chalepensis (Fringed rue) (1) } \\
\text { Zingiber officinale (Ginger) (1) }\end{array}$ \\
\hline Emergency illnesses & $4(1.3)$ & Ocimum lamiifolium (Damakessie) (3) \\
\hline Postpartum bathing & $4(1.3)$ & Eucalyptus globulus (Nech-bahir zaf) (3) \\
\hline Vomiting & $3(0.9)$ & Zingiber officinale (Ginger) (2) \\
\hline $\begin{array}{l}\text { Yemahitsen mitch } \ddagger \\
\text { ('gynaecologic mitch') }\end{array}$ & $3(0.9)$ & $\begin{array}{l}\text { Croton macrostachyus (Bisena) (1) } \\
\text { Ocimum lamiifolium (Damakessie) (1) } \\
\text { Pycnostachys abyssinica (Yeroo) (1) }\end{array}$ \\
\hline Depression & $3(0.9)$ & $\begin{array}{l}\text { Echinops kebericho (Kebericho) (1) } \\
\text { Ruta chalepensis (Fringed rue) (1) } \\
\text { Cinnamomum verum (Cinnamon) (1) }\end{array}$ \\
\hline Well-being and nourishing the fetus & $3(0.9)$ & $\begin{array}{l}\text { Linum usitatissimum (Flaxseed) (2) } \\
\text { Trigonella foenum-graecum (Fenugreek) (1) }\end{array}$ \\
\hline Cough & $2(0.6)$ & $\begin{array}{l}\text { Nigella sativa (Black seed) (1) } \\
\text { Saccharum officinarum (Sugar crystals) (1) }\end{array}$ \\
\hline Birdd§ & $2(0.6)$ & $\begin{array}{l}\text { Allium sativum (Garlic) (1) } \\
\text { Nigella sativa (Black seed) (1) }\end{array}$ \\
\hline
\end{tabular}


Table 3 Continued

\begin{tabular}{|c|c|c|}
\hline Variables & No $(\%)^{*}$ & Most common medicinal plants (no of users) \\
\hline Diarrhoea & $2(0.6)$ & $\begin{array}{l}\text { Ocimum lamiifolium (Damakessie) (1) } \\
\text { Taverniera abyssinica (Dingetegn) (1) }\end{array}$ \\
\hline Sleeping problems & $2(0.6)$ & Artemisia abyssinica (Chikugn) (2) \\
\hline Others & $15(4.7)$ & $\begin{array}{l}\text { Linum usitatissimum (Flaxseed) (3) } \\
\text { Allium sativum (Garlic) (3) } \\
\text { Ocimum lamiifolium (Damakessie) (3) }\end{array}$ \\
\hline
\end{tabular}

*Total percentage may exceed $100 \%$ due to multiple responses.

†Reduction of labour: includes reduced intensity and shortened duration of labour.

‡'Mitch': A febrile illness believed to develop when strong sunlight strikes a part of the body that is sweating or unclean.

§Birdd': an illness typified by a feeling of chills, arthralgia, myalgia, generalised body weakness, pain (particularly chest pain) and coughing. In general, it is characterised by pneumonia/influenza-like symptoms.

ๆOthers includes make labour simple, stomach rambling, quicken labour, prevent 'megagna', fever, facilitation of digestion, tonsillitis, pregnancy associated body/physical illnesses, skin rashes ('Shifta'), abdominal distension/bloating, throat congestion ('Guroroyen siyafinegn'), malaria, appetiser, upper extremity fatigability, for any illness, each with a frequency of one.

JUMC, Jimma University Medical Centre.

drinking milk as antidote ('वYCh'T' in Amharic) against adverse effects from $Z$. officinale, T. abyssinica, $H$. abyssinica and C. verum. Two women reported ingestion of $P$. anisum soup/suspension as countermeasure for poisoning from Z. officinale and C. verum. Eight women used L. usitatissimum for well-being and nourishing of the fetus. One woman reported the use of $O$. lamiifolium to improve fetal movements and breathing. O. lamiifolium, Z. officinale and A. sativum were also reported to be useful for general fetal well-being. Fear of complications to the fetus $(44.5 \%)$ and religious prohibition $(25.9 \%)$ were the common reasons for avoiding use of medicinal plants during pregnancy.

\section{DISCUSSION}

Knowledge; both lay and professional, about medicinal plants use in pregnancy is essential to provide optimal maternal/ fetal care. To the best of our knowledge, this paper is the first to study medicinal plant use during pregnancy among women in an inpatient setting in Ethiopia. This study provides extensive insight into types of medicinal plants, prevalence of use and reasons for use, as well as women's safety concerns and precautions on the medicinal plants they use in pregnancy. These findings are important to healthcare personnel, researchers, policy-makers and pregnant women themselves. Nearly one-third of women (28.6\%) reported use of at least one medicinal plant during pregnancy or at childbirth. Prior studies report global prevalence of use of medicinal plants in pregnancy ranging from $0.9 \%$ to $96.0 \% .{ }^{416}$ Studies from Africa, however, report prevalence of medicinal plant use in pregnancy ranging from $2 \%$ (Ethiopia) to $100 \%$ (Kenya). Variation in prevalence may be explained by several factors including differences in study populations and settings, study inclusion and exclusion criteria as well as data collection methods and definitions of medicinal plants. In some studies, all forms of herbal meal preparations and nutritional supplements were counted ${ }^{4}$ whereas in others, like our study, a more restrictive definition of medicinal plant use was used. In addition, differences in traditional practices, cultures and beliefs about health, may contribute to important difference in prevalence of use of medicinal plants.

The most frequently used medicinal plants during pregnancy were flaxseed (use with caution), damakessie (safety unknown) and papaya (use with caution, it is considered potentially unsafe in large amounts only) (table 2; online supplemental table 4). Our finding is inconsistent with previous studies reported in Africa in which $Z$. officinale, $A$. sativum and $C$. pepo were the commonly used plants. ${ }^{4}$ The pattern of medicinal plant use is also divergent from latest findings from Ethiopia. ${ }^{13} 14$ This may be due to the fact that unlike previous studies, most participants in our study were women in their final stage of pregnancy and might most probably recall the medicinal plants they took in relation to childbirth to a better extent than plants used earlier in pregnancy. This difference in pattern of use from other corners of Ethiopia and regions elsewhere may be due to difference in climate, geographical location (which will affect the types of plants commonly grow in that area) and/or disease prevalence.

Flaxseed is by far the most commonly used medicinal plant, mainly used for induction, reduction, quickening or preparation for labour (table 2). A recent study from Ethiopia had also found similar reason for its use. ${ }^{15}$ 
Table 4 Pregnant women's self-reported safety concerns and experiences with medicinal plants (MPs) at JUMC, Ethiopia, $\mathrm{n}=319$

\section{MPs, reported reasons for contraindication (No of citations)}

Flaxseed: Cause uterine contractions, Flaxseed*: Aloe vera is miscarriage or premature labour (2), Dries up breastmilk (1)

bitter and makes flaxseed preparation unpalatable (1), the woman should stay away from sunlight while/after taking flaxseed preparation (1)

Kossot: Causes uterine stimulation (4) Kosso: Kosso protects the mother from outside person's 'tila' as it may kill her (1), After taking Kosso, the woman should stay at home for 2 days protected from outside person's 'tila' (1)‡

Dingetegna:Harmful during pregnancy, reason unknown (1)§

Dingetegnaף:The woman who took dingetegna should stay at home, outsiders should not be allowed to get in for fear of their 'tila' (1)

Damakessie: Causes uterine stimulation (1)

Tej Sar ${ }^{\star \star \star}$ : Causes uterine stimulation (1), harmful during pregnancy, reason unknown (1)§

Damakessie††: After applying MPs stay at home, going outside is forbidden (1) ${ }^{\star \star}$

Cinnamon†††: Inflammatory to the stomach, thus eat food before taking cinnamon (1)

Ensilalłキ‡: Causes uterine stimulation (1), harmful during pregnancy, reason unknown (1)§

Garlic: Larger dose of garlic is irritant, thus eat food before taking it (1)

Grawa§§§: Causes uterine stimulation Ginger: Stomach irritant, thus (2) harmful during pregnancy, reason unknown (1)§

Black seed: Generally not good for the woman and the fetus, thus better not to take it during pregnancy (1)

Bisanaๆๆๆ: Causes uterine

stimulation (2), harmful to the fetus (1), stay at home,
generally not good for the fetus (1), its forbidden $(1)^{\star \star}$

smell deteriorates health of pregnant

women (1)

Kebericho: Generally not good for the fetus(1) Kebericho††††: Kebericho eat food before taking ginger

(1), beware since ginger decreases appetite (1) and induces fever (1)

Yerooł‡: After applying MPs stay at home, going outside is forbidden (1)

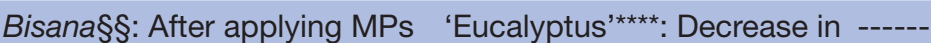
fetus (1)

Black seed: Gastric irritation -------

(3), Loss of appetite (1)

MPs, reported adverse

MPs, reported Side effects drug reactions (No of citations) (No of citations)

Flaxseed: Nausea (4),

Postpartum shivering (1),

Flaxseed: Severe

Diarrhoea (1), Vomiting (1),

Loss of appetite (1), postpartum shivering (1), Loss of consciousness

(1), Uterine rupture (1),

Stillbirth (1)

Kosso: Diarrhoea (2)

Kosso: Severe diarrhoea

(2)

Dingetegna: Severe

diarrhoea (2)

Vomiting (1)

Damakessie: Loss of appetite (1), Bitter (after) taste (1), Sneezing (1)

Chikugn $\uparrow$ : Anencephaly: giving birth to a headless neonate (1)

Cinnamon: Heart burn (1) Cinnamon: Severe heart burn (1)

Garlic: Discomfort to fetus Garlic: Harm to the fetus (1), Gastric irritation (1), Loss (1), Bad mouth smell (1), of appetite (1) Severe heart burn (1)

Ginger: Gastric irritation (2), Ginger: Harm to fetus (1), Heart burn (2), Discomfort to Severe heart burn (1)

appetite (1) Sugar§§§§ : Eye irritation (1) -----worsen the Mitch 㧊 disease (1)

Astenagr/Etse faris to the fetus (1), Causes uterine stimulation (3), Generally not good for pregnant woman and the fetus (1)

Fringed rue: Kebericho should Fringed rue: Loss of not be taken with rue because appetite (1)

it will worsen the nausea (1), beware since it induces fever (1), There is a plant interacting with rue, but forgot its name

(1)

'Baruda' plant ${ }^{\star \star \star * *}$ : Causes uterine stimulation (1) 


\begin{tabular}{|c|c|c|c|}
\hline $\begin{array}{l}\text { MPs, reported reasons for } \\
\text { contraindication (No of citations) }\end{array}$ & $\begin{array}{l}\text { MPs, reported precautions } \\
\text { (No of citations) }\end{array}$ & $\begin{array}{l}\text { MPs, reported Side effects } \\
\text { (No of citations) }\end{array}$ & $\begin{array}{l}\text { MPs, reported adverse } \\
\text { drug reactions } \\
\text { (No of citations) }\end{array}$ \\
\hline $\begin{array}{l}\text { Endod†††††: Causes uterine } \\
\text { stimulation (1) }\end{array}$ & ------ & ------ & ------ \\
\hline
\end{tabular}

Metere㧊抽 Harmful to the fetus (1)

Feto§§§§§: Causes uterine

stimulation (1)

${ }^{*}$ After consuming Flaxseed (Linum usitatissimum) preparation the woman should stay at home, exposure to sunlight results in Mitch disease. †Hagenia abyssinica.

¥'Tila', loosely translated means the shade of a person that is believed to have pernicious effect.

$\S$ The plant is harmful during pregnancy, but the woman does not know the reason for contraindication.

१Taverniera abyssinica.

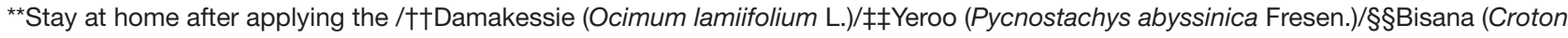
macrostachyus Hochst) mixture formulation, going outside is forbidden; Otherwise there is relapse of the disease.

††Damakessie (Ocimum lamiifolium L).

¥¥Yeroo (Pycnostachys abyssinica Fresen).

$\S \S$ Bisana (Croton macrostachyus)

ПๆArtemisia abyssinica Sch.Bip. ex A.Rich.

${ }^{* \star *}$ Cymbopogon citratus (DC.) Stapf.

†††Cinnamomum verum.

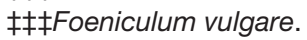

$\S \S \S$ Vernonia amygdalina.

१ๆ१Croton macrostachyus.

${ }^{* * \star *}$ Eucalyptus globulus.

†††Echinops kebericho.

$\ddagger \ddagger \ddagger \ddagger$ Mitch: A febrile illness believed to develop when strong sunlight strikes a part of the body that is sweating or unclean.

$\S \S \S \S S a c c h a r u m$ officinarum $\mathrm{L}$.

ๆๆๆๆDatura stramonium $\mathrm{L}$.

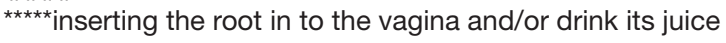

††††Phytolacca dodecandra L'Hér.

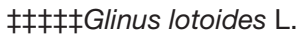

$\S \S \S \S \S L e p i d i u m$ sativum.

JUMC, Jimma University Medical Centre.

In other African countries, however, seed oil from $R$. communis was the most frequently used medicinal plant product to stimulate labour. ${ }^{4}$ The most probable reasons for the disparity in the type of medicinal plant used for labour induction may be differences in geographical distribution of plants and cultural beliefs.

In line with previous studies, ${ }^{33} 34$ women reported side effects and safety concerns related to use of flaxseed in relation to labour (table 4). A precautious consumption of flaxseed is recommended in pregnancy and lactation due to its side effects and adverse effects when consumed in excessive quantity. ${ }^{34}$ In remote rural areas in Ethiopia where access to health facilities is limited, use of $L$. usitatissimum may be perceived as the best option to induce or shorten labour.

O. lamiifolium was the second most used medicinal plant during pregnancy in our study. It was mainly used for treatment of an illness called 'Mitch' alone or with other medicinal plants (table 3). 'Mitch' is a culturally common illness in Ethiopia and is a local name given to a febrile illness characterised by headache, fever, rash, inflammation, joint pain, back pain, chills, sweat, loss of appetite, Herpes labialis, muscle spasm and in severe cases, diarrhoea. ${ }^{135}$ 'Mitch' develops when strong sunlight strikes a part of the body that is sweating or unclean, ${ }^{36}$ and in general after engaging in tasks that expose one to strong smells or smoke. ${ }^{137}$ Our study found that 'Mitch' also affects female reproductive organs when it is exposed to excessive sunlight, which they refer it to as 'Yemahitsen Mitch' ('gynaecologic mitch) (table 3). In general our result agrees with the findings of Ethiopians at home ${ }^{15}$ and in diaspora ${ }^{1}$ regarding 'Mitch' and its treatment. Studies of the leaf extract of $O$. lamiifolium have shown analgesic effects in mice $^{38}$ that support its traditional use against Mitch. O. lamiifolium is considered relatively safe and has not demonstrated any sign of acute toxicity up to the dose of $2000 \mathrm{mg} / \mathrm{kg}$ body weight in experimental mice. ${ }^{39}$

C. papaya and Z. officinale were the third and the fourth commonly used plants, respectively. Several women in this study claimed that papaya softens their birth canal ('uterus') making them healthy and ready for childbirth (table 2). Moreover, they claimed that consumption of cold papaya would soothe their gastrointestinal tract relieving them from heartburn, gastritis and cramps (table 3). Animal studies suggest that unlike its abortifacient property at larger dose, normal consumption of ripe papaya during pregnancy may not pose any developmental toxicity and teratogenicity. ${ }^{40}$ 
Although previous studies, also in Ethiopia, showed that pregnant women commonly use ginger for treating NVP, ${ }^{1452028}$ our study found that it was mainly used for common colds and influenza in pregnancy. This could be due to the fact that previous studies involved mainly women in their earlier stages of pregnancy in which NVP is common. Concerning safety, evidences suggest that ginger did not have harmful maternal or neonatal effects. ${ }^{14}$ Its side effects reported in our study were also similar with previous reports. ${ }^{1}$

Several sociodemographic factors were associated with use of medicinal plants in pregnancy (table 1). We found that women who did not have access to health facility (including health posts) were seven times more likely to use medicinal plants than their counterparts. This is in line with other studies showing that in Africa people use traditional medicine when facilities are either unavailable or unaffordable. ${ }^{42}$ Similarly, women admitted in maternity ward were threefold as likely to use medicinal plants as their counterparts. Most women in the maternity ward were in their final stage of pregnancy and might be using more medicinal plants for childbirth than those admitted in gynaecology ward in which hyperemesis and abortions predominate. Similarly, women who used khat or consumed alcohol as well as conventional medicine were twice or more as likely to use medicinal plants as their counterparts, and may either indicate a higher willingness to intake different substances in pregnancy and/or higher morbidity. Since interactions between medicinal plants and conventional medicines may occur and potentially may cause complications, ${ }^{4}{ }^{15} 41$ caution with concomitant use should be recommended. Healthcare personnel at the wards were often not informed; neither involved in decisions nor aware about the women's use of medicinal plants in relation to childbirth. As pregnancy is a time of particular vulnerability, cautious use of medicinal plants is necessary and healthcare professionals should ask women about their use and provide them evidence-based information.

Despite the size and extensive data collection, this study has several limitations that should be taken into consideration. First, JUMC is a tertiary referral hospital with a larger proportion of women with pregnancy complications. Our findings may not be representative of women in secondary or primary care. Second, as this study was based in southwest Ethiopia, participants were mostly Muslims and from the Oromo ethnic group. These groups had a lower use of medicinal plants in pregnancy compared with participants who were Orthodox and from the Dawuro ethnic group. Our results will consequently not be generalisable to the entire country. This finding underpins the importance of including ethnic and religious background information in studies on medicinal plants, as it will have large impacts on utilisation and reporting patterns. Third, data were collected based on pregnant women's self-report and thus depended on their accuracy of recall and reporting as well as willingness to disclose utilisation. It may well be that the use of medicinal plants is underestimated due to poor recall or under-reporting. This may be especially important during face-to-face interviews for certain medicinal herbs, recreational or illicit drugs that are culturally unacceptable. Actual medicinal plant use in pregnancy may therefore be higher in real life, and/ or different in other populations and regions in Ethiopia.

\section{CONCLUSION}

Almost one-third of women at the tertiary hospital in Ethiopia used medicinal plants during pregnancy, most frequently to prepare, induce, reduce the intensity or shorten duration of labour. Seeds and dry plant material was mostly used, sugar the most common excipient and oral route of administration was predominant. The most frequently used medicinal plants were Linum usitatissimum L. (flaxseed-use with caution) $(22.0 \%)$, Ocimum lamiifolium L. (damakessie-safety unknown) (3.6\%), and Carica papaya L. (papaya-use with caution) $(3.1 \%)$. O. lamiifolium was mainly used for treatment of a culturally common illness in Ethiopia called 'Mitch', a febrile illness believed to develop after exposure to excessive sunlight. Few women reported safety concerns regarding medicinal plant use in pregnancy. The most important factors associated with use of medicinal plants in pregnancy were lack of access to healthcare facilities, hospitalisation in the maternity ward and social drug use.

Given that women use unsafe plants during the pregnancy, increased awareness about potential benefits or risks of medicinal plants use during the pregnancy among healthcare professionals and patients, and increased access to healthcare facilities are important in order to promote safer pregnancies and better health outcomes for women and their unborn children.

\section{Author affiliations}

${ }^{1}$ Department of Community Medicine and Global Health, Institute of Health and Society, Faculty of Medicine, University of Oslo, Oslo, Norway

${ }^{2}$ Division of Social and Administrative Pharmacy, School of Pharmacy, Faculty of Health Sciences, Institute of Health, Jimma University, Jimma, Ethiopia

${ }^{3}$ Department of Obstetrics and Gynaecology, Faculty of Medical Sciences, Institute of Health, Jimma University, Jimma, Ethiopia

${ }^{4}$ Pharmacoepidemiology and Drug Safety Research Group, Department of Pharmacy, Faculty of Mathematics and Natural Sciences, University of Oslo, Oslo, Norway

Correction notice This article has been corrected since it was first published. The formatting errors of table 1 has been corrected now.

Twitter Seid Mussa Ahmed @SEID and Hedvig Nordeng @Pharma_Nordeng

Acknowledgements We are grateful to the pregnant women admitted at JUMC who generously shared with us information about their medicinal plant use. The authors owe a debt of gratitude to the enumerators who skilfully collected the data. We would like to thank Norwegian PhD School in Pharmaceutical Sciences for the travel grant assistance for the data collection. Special thanks go to the Norwegian Loan Fund (Lånekassen) for granting scholarship for the PhD student (SMA) in the University of Oslo. The authors thank PharmaSafe research group, University of Oslo for funding to cover open access fees. The authors are also indebted to Dr. Ibrahimu Mdala for assistance with data analysis.

Contributors SMA and HN conceived the idea for the study and its design. SMA collected, analysed and interpreted data and drafted the manuscript. YAA and JS participated in study coordination. SMA and HN revised and finalised the manuscript. SMA, HN, JS and YAA critically reviewed the manuscript and contributed intellectual content. All authors read and approved the final manuscript. 
Funding The authors have not declared a specific grant for this research from any funding agency in the public, commercial or not-for-profit sectors.

Competing interests None declared.

Patient consent for publication Not required

Ethics approval This study was approved by Jimma University Institute of health Institutional Review Board (IRB) (ref. no. IHRPGC 7206/07) in Ethiopia, and Regional Committees for Medical and Health Research Ethics (REK Sør-Øst B) (Ref.no. 2015/2135) in Norway.

Provenance and peer review Not commissioned; externally peer reviewed.

Data availability statement Data are available on reasonable request.

Supplemental material This content has been supplied by the author(s). It has not been vetted by BMJ Publishing Group Limited (BMJ) and may not have been peer-reviewed. Any opinions or recommendations discussed are solely those of the author(s) and are not endorsed by BMJ. BMJ disclaims all liability and responsibility arising from any reliance placed on the content. Where the content includes any translated material, BMJ does not warrant the accuracy and reliability of the translations (including but not limited to local regulations, clinical guidelines, terminology, drug names and drug dosages), and is not responsible for any error and/or omissions arising from translation and adaptation or otherwise.

Open access This is an open access article distributed in accordance with the Creative Commons Attribution Non Commercial (CC BY-NC 4.0) license, which permits others to distribute, remix, adapt, build upon this work non-commercially, and license their derivative works on different terms, provided the original work is properly cited, appropriate credit is given, any changes made indicated, and the use is non-commercial. See: http://creativecommons.org/licenses/by-nc/4.0/.

\section{ORCID iD}

Seid Mussa Ahmed http://orcid.org/0000-0003-3426-5296

\section{REFERENCES}

1 Hailemeskel B, Fullas F, Habte A. A review of natural remedies commonly used by Ethiopian immigrants in the USA. Curr Res Integr Med 2017;2:31-6.

2 Jamshidi-Kia F, Lorigooini Z, Amini-Khoei H. Medicinal plants: past history and future perspective. J Herbmed Pharmacol 2018;7:1-7.

3 Mazzari ALDA, Prieto JM. Herbal medicines in Brazil: pharmacokinetic profile and potential herb-drug interactions. Front Pharmacol 2014;5:162.

4 Ahmed SM, Nordeng H, Sundby J, et al. The use of medicinal plants by pregnant women in Africa: a systematic review. J Ethnopharmacol 2018;224:297-313.

5 Shewamene Z, Dune T, Smith CA. The use of traditional medicine in maternity care among African women in Africa and the diaspora: a systematic review. BMC Complement Altern Med 2017;17:382.

6 United States Central Intellingence Agency (CIA). The world fact book, Africa: Ethiopia, 2018. Available: https://www.cia.gov/theworld-factbook/countries/ethiopia/\#people-and-society [Accessed 13 Feb 2019].

7 Ficquet E. Interfaith relations between Christianity and Islam in Ethiopia, 2019. Available: https://www.sciencespo.fr/ceri/fr/ oir/interfaith-relations-between-christianity-and-islam-ethiopia [Accessed 20 Feb 2021].

8 Ethiopian Public Health Institute (EPHI). Traditional and modern medicine research, 2019. Available: http://www.ephi.gov.et/index php/research/traditional-modern-medicine [Accessed 25 Feb 2019].

9 Laelago T, Yohannes T, Lemango F. Prevalence of herbal medicine use and associated factors among pregnant women attending antenatal care at public health facilities in Hossana town, southern Ethiopia: facility based cross sectional study. Arch Public Health 2016;74:7.

10 United Nations Children's Fund (UNICEF). Maternal and newborn health disparities country profiles, 2018. Available: https://data. unicef.org/resources/maternal-newborn-health-disparities-countryprofiles [Accessed 05 Sept 2019].

11 Ahmed SM, Sundby J, Aragaw YA, et al. Self-Medication and safety profile of medicines used among pregnant women in a tertiary teaching hospital in Jimma, Ethiopia: a cross-sectional study. Int $J$ Environ Res Public Health 2020;17:3993.

12 Bayisa B, Tatiparthi R, Mulisa E. Use of herbal medicine among pregnant women on antenatal care at nekemte Hospital, Western Ethiopia. Jundishapur J Nat Pharm Prod 2014;9:e17368.
13 Jambo A, Mengistu G, Sisay M, et al. Self-Medication and contributing factors among pregnant women attending antenatal care at public hospitals of Harar town, Ethiopia. Front Pharmacol 2018;9:1063.

14 Mekuria AB, Erku DA, Gebresillassie BM, et al. Prevalence and associated factors of herbal medicine use among pregnant women on antenatal care follow-up at University of Gondar referral and teaching Hospital, Ethiopia: a cross-sectional study. BMC Complement Altern Med 2017;17:86.

15 Nega SS, Bekele HM, Meles GG, et al. Medicinal plants and concomitant use with pharmaceutical drugs among pregnant women. J Altern Complement Med 2019;25:427-34.

16 Hall HG, Griffiths DL, McKenna LG. The use of complementary and alternative medicine by pregnant women: a literature review. Midwifery 2011;27:817-24.

17 Westfall RE. Herbal healing in pregnancy: women's experiences. J Herb Pharmacother 2003;3:17-39.

18 Kennedy DA, Lupattelli A, Koren G, et al. Herbal medicine use in pregnancy: results of a multinational study. BMC Complement Altern Med 2013;13:355.

19 Ahmed M, Hwang JH, Choi S, et al. Safety classification of herbal medicines used among pregnant women in Asian countries: a systematic review. BMC Complement Altern Med 2017;17:489.

20 Ahmed M, Hwang JH, Hasan MA, et al. Herbal medicine use by pregnant women in Bangladesh: a cross-sectional study. BMC Complement Altern Med 2018;18:333.

21 Kennedy DA, Lupattelli A, Koren G, et al. Safety classification of herbal medicines used in pregnancy in a multinational study. BMC Complement Altern Med 2016;16:102.

22 Godlove M. Prevalence of herbal medicine use and associated factors among pregnant women attending antenatal clinic at Mbeya Refferal Hospital in 2010 (M.Sc. Thesis). Tanzania: Muhimbili University of Health and Allied Sciences, Dar es salaam, 2011. http://dspace. muhas.ac.tz:8080/xmlui/bitstream/handle/123456789/41/Mbwanji\% 20Dissertation.pdf?sequence=1\&isAllowed=y [Accessed 05 Oct 2019]

23 Segni $\mathrm{H}$, Ayana $\mathrm{D}$, Jarso $\mathrm{H}$. Prevalence of hyperemesis gravidarum and associated factors among pregnant women at Jimma University medical center, South West Ethiopia: a cross-sectional study. EC Gynaecol 2016;3:376-87.

24 Jimma University Specialized hospital, 2017. Available: http://www. ju.edu.et/jimma-university-specialized-hospital-jush [Accessed 13 Sep 2018].

25 Kish L. Survey sampling. New York, NY,USA: John Wiley \& Sons, Inc, 1965.

26 Mureyi DD, Monera TG, Maponga CC. Prevalence and patterns of prenatal use of traditional medicine among women at selected Harare clinics: a cross-sectional study. BMC Complement Altern Med 2012;12:164.

27 Mkize GT. An assessment of use of traditional medicine in pregnancy \& associated factors among black south african women delivering in bertha gxowa hospital (M.Sc. Thesis). Johannesburg, South Africa: University of the Witwatersrand, 2015. http://wiredspace.wits.ac.za/ handle/10539/17340?show=full

28 Gall A, Shenkute Z. Ethiopian traditional and herbal medications and their interactions with conventional drugs. Available: https:// ethnomed.org/clinical/pharmacy/ethiopian-herb-drug-interactions [Accessed 17 Oct 2018].

29 Gedif T, Hahn H-J. The use of medicinal plants in self-care in rural central Ethiopia. J Ethnopharmacol 2003;87:155-61.

30 Mills E, Duguoa J-J, Perri D. Herbal medicines in pregnancy and lactation: an evidence-based approach. London ; New York: Taylor \& Francis, 2006.

31 Mills S, Bone K. The essential guide to herbal safety. St. Louis, Mo: Elsevier Churchill Livingstone, 2005.

32 Gardner Z, McGuffin M. American Herbal Products Association. American herbal products association's botanical safety handbook. 2nd edn. Boca Raton, FL: CRC Press, 2013

33 Zamawe C, King C, Jennings HM, et al. Effectiveness and safety of herbal medicines for induction of labour: a systematic review and meta-analysis. BMJ Open 2018;8:e022499.

34 Gokhale S, Sahu A. Pharmacological properties of flaxseed, Linum usitatissimum Linn., as a potential medicinal plant: An overview. World J Pharm Sci 2016;4:207-15.

35 Hodes RM, Teferedegne B. Traditional beliefs and disease practices of Ethiopian Jews. Isr J Med Sci 1996;32:561-7.

36 Hodes R. Cross-cultural medicine and diverse health beliefs. Ethiopians abroad. West J Med 1997;166:29-36.

37 Kifle H, Woldu AM, Asres K. Bucar F: composition, antimicrobial and free-radical scavenging properties of the essential oil of Damakese (Ocimum lamiifolium): A popular home remedy in Ethiopia. Int $J$ Essen Oil Ther 2007:1:110-6. 
38 Debella A, Makonnen E, Abebe D, et al. Pain management in mice using the aqueous and ethanol extracts of four medicinal plants. East Afr Med J 2003;80:435-9.

39 Kefe A, Giday M, Mamo H, et al. Antimalarial properties of crude extracts of seeds of Brucea antidysenterica and leaves of Ocimum lamiifolium. BMC Complement Altern Med 2016;16:118.
40 Oderinde O, Noronha C, Oremosu A, et al. Abortifacient properties of aqueous extract of Carica papaya (Linn) seeds on female SpragueDawley rats. Niger Postgrad Med J 2002;9:95-8.

41 El Haij M, Holst L. Herbal medicine use during pregnancy: a review of the literature with a special focus on sub-Saharan Africa. Front Pharmacol 2020;11:866. 